\title{
CARACTERÍSTICAS PRODUTIVAS DE PASTAGENS DE MILHETO OU CAPIM SUDÃO SUBMETIDAS AO PASTEJO CONTÍNUO DE VACAS PARA ABATE
}

\author{
Rangel Fernandes Pacheco ${ }^{1}$, Dari Celestino Alves Filho ${ }^{2}$, Ivan Luiz Brondani ${ }^{2}$, José \\ Laerte NornBerG ${ }^{2}$, Luiz ANGelo Damian PizZuti ${ }^{1}$, Álisson Marian CAllegaro ${ }^{1}$ \\ ${ }^{1}$ Pós-graduandos da Universidade Federal de Santa Maria, Santa Maria, RS, Brasil - rangelzootec@hotmail.com \\ ${ }^{2}$ Professores Doutores da Universidade Federal de Santa Maria, Santa Maria, RS, Brasil
}

Objetivou-se avaliar os parâmetros produtivos das pastagens de milheto (Pennisetum glaucum (L.) R. BR) e capim sudão (Sorghum bicolor cv. sudanense) submetidas ao pastejo contínuo de vacas destinadas ao abate. Foram utilizadas 22 vacas oriundas do cruzamento entre as raças Charolês e Nelore, mantidas sob pastejo contínuo, em pastagens de milheto ou capim sudão ao longo de 63 dias experimentais, divididos em três períodos ( 21 dias cada). $\mathrm{O}$ delineamento experimental foi $\mathrm{o}$ inteiramente casualizado com dois tratamentos e três períodos, sendo cinco repetições (área). Os parâmetros produtivos das pastagens foram similares na comparação entre os tratamentos $(\mathrm{P}<0,05)$. O ciclo vegetativo das pastagens não alteraram a massa de forragem $(1.606,93 \mathrm{~kg}$ e $1.617,47$ de matéria seca (MS)/ha) e a oferta de forragem $(9,42$ e $8,29 \mathrm{~kg}$ de $\mathrm{MS} / 100 \mathrm{~kg}$ de $\mathrm{PV})$ das pastagens de milheto ou capim sudão. No entanto, as médias para taxa de acúmulo de matéria seca e proteína bruta demonstraram maiores valores nos primeiros 21 dias de utilização das pastagens (130,77 kg de MS/ha e $17,04 \mathrm{~g} / \mathrm{kg}$ de MS), seguidas de reduções nos dois últimos períodos, sendo as médias do segundo período $(65,53 \mathrm{~kg} / \mathrm{ha}$ de MS e $12,96 \mathrm{~g} / \mathrm{kg}$ de $\mathrm{MS}$ ) superior à do terceiro período experimental (36,13 kg/ha de MS e $10,01 \mathrm{~g} / \mathrm{kg}$ de MS). Os valores para fibra em detergente neutro foram similares nos dois períodos iniciais $(48,81 ; 49,01 \mathrm{~g} / \mathrm{kg}$ de MS), seguida de aumento nos últimos 21 dias de utilização das pastagens $(56,54 \mathrm{~g} / \mathrm{kg}$ de MS). A taxa de lotação em $\mathrm{kg} / \mathrm{ha}$ de PV demonstrou interação entre tratamento e período; no entanto, os valores médios entre os tratamentos foram similares $(1741,1 \mathrm{~kg} / \mathrm{ha}$ de PV para milheto e 1881,7 $\mathrm{kg} / \mathrm{ha}$ de PV para sudão). O ganho de peso médio diário não diferiu entre os tratamentos (1,04 para milheto e 0,96 para sudão). A variável ganho de peso vivo por área $(4,18$; $4,55 \mathrm{~kg} / \mathrm{ha}$ de PV) foi similar nos primeiros 42 dias de utilização das pastagens (período 1-21 e 22-42 dias; respectivamente) e superiores a dos últimos 21 dias experimentais $(2,39 \mathrm{~kg} / \mathrm{ha}$ de PV). Pastagens de milheto ou capim sudão se equivalem em relação às características produtivas, sob sistemas de pastejo contínuo com vacas de descarte.

PALAVRAS-CHAVE: ciclo vegetativo, ganho médio diário, oferta de forragem, proteína bruta, sorghum, taxa de lotação.

\section{PRODUCTIVITY CHARACTERISTICS OF SUDAN GRASS OR PEARL MILLET PASTURES SUBMITTED TO CONTINUOUS GRAZING BY CULLING COWS}

\section{ABSTRACT}

This study aimed to evaluate the productive parameters of pearl millet (Pennisetum glaucum (L.) R. BR) and Sudan grass (Sorghum bicolor cv. Sudanense) pastures, under continuous grazing by cows destined to slaughter. We used 22 crossbred Charolais and Nellore cows, kept under continuous grazing on Sudan grass or pearl millet pastures, over 63 experimental days, divided into three periods (21 days each). The experimental design was completely randomized with two treatments and three periods, with five replicates (area). The productive 
parameters of the pastures were similar when treatments were compared $(\mathrm{P}<0.05)$. The growing cycle of pastures did not affect forage mass $(1617.47$ and $1606.93 \mathrm{~kg}$ of dry matter $(\mathrm{DM}) / \mathrm{ha})$ and forage offer $(9.42$ and $8.29 \mathrm{~kg}$ of $\mathrm{DM} / 100 \mathrm{~kg} \mathrm{BW}$ ) on pearl millet or Sudan grass pastures. However, the average rate of accumulation of dry matter and crude protein showed higher values on the first 21 days of pasture use $(130.77 \mathrm{~kg} \mathrm{DM} / \mathrm{ha}$ and $17.04 \mathrm{~g} / \mathrm{kg}$ $\mathrm{DM})$, followed by reductions in the last two periods, and the averages of the second period $(65.53 \mathrm{~kg} \mathrm{DM} / \mathrm{ha}$ and $12.96 \mathrm{~g} / \mathrm{kg} \mathrm{DM})$ were higher than those of the third experimental period $(36.13 \mathrm{~kg} \mathrm{DM} / \mathrm{ha}$ and $10.01 \mathrm{~g} / \mathrm{kg}$ DM). The values for neutral detergent fiber were similar in the two earlier periods $(48.81,49.01 \mathrm{~g} / \mathrm{kg} \mathrm{DM})$, followed by an increase in the last 21 days of pasture use $(56.54 \mathrm{~g} / \mathrm{kg} \mathrm{DM})$. The stocking rate in $\mathrm{kg} / \mathrm{ha}$ of $\mathrm{BW}$ showed an interaction between treatment and period, however, the mean values were similar between treatments $(1741.1 \mathrm{~kg} / \mathrm{ha}$ of the $\mathrm{BW}$ for pearl millet and $1881.7 \mathrm{~kg} / \mathrm{ha}$ of BW for Sudan grass). The average daily live weight gain did not differ between treatments (1.04 for pearl millet and 0.96 for Sudan). The average daily gain per area $(4.18,4.55 \mathrm{~kg} / \mathrm{ha}$ of BW) was similar on the first 42 days of pasture use and higher than on the last 21 experimental days $(2.39 \mathrm{~kg} / \mathrm{ha}$ of BW). Pearl millet or Sudan grass pastures are equivalent with respect to the production characteristics under continuous grazing by culling cows.

KEYWORDS: average daily gain, crude protein, forage supply, sorghum, stocking, vegetative cycle.

\section{INTRODUÇÃO}

As pastagens anuais de estação quente devem apresentar alta capacidade de suporte e qualidade suficiente para que os animais possam expressar seus potenciais genéticos dentro de um modelo viável de sistema de produção. No Rio Grande do Sul, há décadas o milheto (Pennisetum glaucum (L.) R. BR) é reconhecido como forrageira de grande potencial para a produção de bovinos de corte $^{1}$. A elevada capacidade de suporte aliada a satisfatórios ganhos de peso vivo por hectare/dia torna viável a utilização dessa espécie em diferentes sistemas de produção, no período entre dezembro a abril. Entretanto, as constantes estiagens ocorridas justamente nesses meses, que assolaram o estado nessa última década, fizeram com que os produtores buscassem alternativas à alimentação dos bovinos para esse período, fazendo com que espécies como o capim sudão (Sorghum bicolor cv. sudanense) despontassem como uma possível alternativa para a alimentação dos bovinos.

Trabalhos desenvolvidos no centro do país destacam a alta capacidade de produção de forragem e resistência a déficits hídricos de híbridos do capim sudão consorciado com sorgo (Sorghum bicolor cv. bicolor) ${ }^{2}$; no entanto, esses estudos não foram desenvolvidos com a interação permanente do animal sobre a pastagem e tampouco o capim sudão foi avaliado sem o propósito de formação de híbridos. $\mathrm{O}$ fato de o capim sudão apresentar resistência ao déficit hídrico e alta produção de forragem foi suficiente para lhe serem atribuídos méritos, semelhantes aos do milheto, para a produção de bovinos de corte, mesmo sem comprovações científicas que confirmem tal hipótese, o que torna fundamental o desenvolvimento de pesquisas voltados ao capim sudão.

Dentre as categorias de bovinos, a terminação de vacas, além de representar uma importante fonte de receita para as propriedades, tem atendido boa parte da demanda de carne bovina pelos brasileiros $^{3}$. Na última década, o abate de fêmeas bovinas no Brasil girou em torno de $40 \%$ dos animais abatidos, sendo a categoria que apresentou o maior aumento na produção de carne bovina do país (aproximadamente $8 \%)^{4}$. Esses números evidenciam a relevância da categoria em todo o segmento da cadeia produtiva da carne bovina no Brasil. Contudo, boa parte desses animais, quando descartados da reprodução antes do período de monta (novembro a fevereiro), são alimentados em pastagens nativas, característica que muitas vezes inviabiliza sua comercialização no período de verão. Dessa forma, a avaliação da produtividade dessa categoria em pastagens cultivadas de estação quente pode gerar informações importantes em relação ao manejo das pastagens e à terminação de vacas.

Diante disso, objetivou-se avaliar a produtividade de pastagens de milheto ou capim sudão, submetidas ao pastejo contínuo de vacas para abate.

\section{MATERIAL E MÉTODOS}

$\mathrm{O}$ experimento foi desenvolvido no Laboratório de Bovinocultura de Corte do Departamento de Zootecnia da Universidade Federal de Santa Maria. A instituição está localizada no município de Santa Maria-RS. A área experimental situa-se na Depressão Central do Rio Grande do Sul, altitude de $95 \mathrm{~m}$, latitude $29^{\circ} 43^{\prime}$ sul e longitude $53^{\circ} 42^{\prime}$ oeste. O clima da região é subtropical úmido, conforme classificação de Köppen. $\mathrm{O}$ solo é classificado como Argissolo Vermelho distrófico arênico, integrante da unidade de mapeamento São Pedro.

A área experimental utilizada foi de 16 hectares, dividida em doze piquetes, sendo seis para 
cada tratamento, cinco deles como piquetes testes (média de 1 ha cada) e mais um para manutenção dos animais reguladores (média de $3 \mathrm{ha}$ ). $\mathrm{O}$ preparo do solo foi realizado a partir de gradagem (grade aradora) à profundidade de $15 \mathrm{~cm}$ seguida por gradagem leve (grade niveladora). A semeadura ocorreu nos dias 28 e 29 de novembro de 2010, com $20 \mathrm{~kg} / \mathrm{ha}$ de semente de milheto (Pennisetum glaucum (L.) R. BR) e $20 \mathrm{~kg} / \mathrm{ha}$ de semente de capim sudão (Sorghum bicolor cv. sudanense), em base de $100 \%$ o valor cultural, distribuídas a lanço. O manejo de adubação foi realizado com base na análise química, realizada em novembro de 2010, que apresentou os seguintes valores: $\mathrm{pH}$ em $\mathrm{H}_{2} \mathrm{O}=4,96$; $\mathrm{P}=8,1$ (Mehlich-1); $\mathrm{K}=73,2 \mathrm{mg} / \mathrm{dm}^{3} ; \mathrm{Ca}^{2^{+}}=2,43$; $\mathrm{Al}^{3+}=1,61 \mathrm{cmol}_{\mathrm{c}} / \mathrm{dm}^{3}(\mathrm{KCl} 1 \mathrm{~mol} / \mathrm{L})$. Foram aplicados $225 \mathrm{~kg} / \mathrm{ha}$ de NPK na formula 5-20-20, bem como $72 \mathrm{~kg} / \mathrm{ha}$ de $\mathrm{N}$ na forma de ureia, sendo essa última dividida em duas aplicações, que ocorreram nos dias 06/01/2011 (45 kg/ha) e 27/01/2011 (27 kg/ha).

Foram utilizadas 22 vacas oriundas do mesmo rebanho e do cruzamento entre as raças Charolês e Nelore, com idade média inicial de $8 \pm$ 2,21 anos e peso vivo médio inicial de $448 \pm 43,57$ $\mathrm{kg}$. Os animais foram divididos em dois tratamentos denominados conforme a espécie de pastagem: Milheto, para as pastagens de milheto manejadas com pastejo contínuo, e Sudão, para as pastagens de capim sudão manejadas com pastejo contínuo. Cada tratamento foi composto por cinco repetições de área, com número variável de animais dentro das repetições, sendo quatro piquetes com duas vacas cada e um com três vacas.

A utilização das pastagens iniciou-se em 29/12/2010 com a entrada dos animais para a redução da massa de forragem, com intuito de induzir o perfilhamento. A permanência das vacas nas pastagens nesse período se estendeu até o dia 03/01/2011, momento no qual foram retiradas com o intuito de estabelecer a massa de forragem desejada para o início do período experimental. Dia 23/01/2011 procedeu-se a entrada das vacas testes nas respectivas áreas para adaptação e em 30/01/2011 iniciou-se o período experimental. O método de pastejo foi o contínuo, com lotação contínua, com número variável de animais reguladores com o objetivo de manter a massa de forragem em $2.000 \mathrm{~kg} / \mathrm{ha}$ de massa seca.

$\mathrm{O}$ experimento compreendeu 63 dias, transcorrendo três períodos de 21 dias cada, denominados: 1-21, que se estendeu de 30/01/2011 a $19 / 02 / 2011 ; 22-42$, que se estendeu de 20/02/2011 a $12 / 03 / 2011$, e $43-63$, que correspondeu ao intervalo entre 03/03/2011 a 13/03/2011. Ao início e final de cada período foram determinados os parâmetros produtivos das pastagens.

A massa de forragem (MF) foi estimada a partir da técnica de estimativa visual com dupla amostragem, conforme metodologia sugerida por WILM et al. ${ }^{5}$. De cada corte, foi retirada uma amostra e, posteriormente, essas amostras foram homogeneizadas e divididas em duas sub-amostras, uma para a determinação do teor de matéria parcialmente seca do pasto (MPS) e outra para a separação manual dos componentes morfológicos e botânicos da pastagem.

O teor de MPS foi determinado por secagem das amostras em estufa com circulação forçada de ar a $55^{\circ} \mathrm{C}$ por 72 horas. Após a separação botânica e secagem dos componentes da pastagem, foi determinada a participação percentual de lâmina foliar, pseudocolmo (colmo + bainha foliar), material morto das espécies alvo do estudo e outras espécies. A partir da proporção de folha e colmo foi determinada a relação folha:colmo $(\mathrm{F} / \mathrm{C})$.

A taxa de acúmulo (TAD) foi estimada com o auxílio de três gaiolas de exclusão ao pastejo por piquete, conforme descrito por Pizzuti et al. ${ }^{6}$, com avaliações a cada 21 dias. A massa de forragem disponível $(\mathrm{kg} / \mathrm{ha} /$ dia de MS) foi determinada a partir da razão da soma da TAD com a MF do período pelo número de dias do período (21 dias).

Para a determinação da oferta de forragem (OF), foi calculada a razão da MF disponível pela taxa de lotação, sendo expressa como kg de MS/100 $\mathrm{kg}$ de peso $\mathrm{vivo} / \mathrm{dia}^{7}$. A oferta de lâminas foliares (OFL) foi determinada por meio do produto da OF pelo percentual de lâminas foliares da massa de forragem disponível.

As perdas de forragem foram estimadas por meio da demarcação de seis pontos amostrais em cada piquete, distribuídos em duas transectas. Em cada ponto foram enterradas duas estacas de madeira, rente ao solo, próximas o suficiente para ser colocado um quadro de $0,25 \mathrm{~m}^{2}$ entre elas. Nesses locais, a cada 21 dias, eram recolhidos do solo toda a forragem considerada não consumida pelo animal e que não mais estava ligada à planta, conforme descrito por Pizzuti et al. ${ }^{6}$. Cada amostra foi seca em estufa de circulação de ar forçado a $55^{\circ} \mathrm{C}$ e, posteriormente, pesada e extrapolada para 1 ha, para a determinação de quanto de forragem $(\mathrm{kg} / \mathrm{ha}$ de MS) foi perdida do pastejo durante o período.

Para a avaliação dos teores bromatológicos do pasto consumido pelos animais, foi utilizada a técnica de simulação de pastejo, conforme Euclides et $\mathrm{al}^{8}{ }^{8}$. As amostras foram parcialmente secas e moídas em moinho do tipo willey e posteriormente analisadas quanto aos teores de matéria seca (MS), nitrogênio total $(\mathrm{N})$ e fibra em detergente neutro (FDN). Os teores de MS foram determinados por 
secagem em estufa a $105^{\circ} \mathrm{C}$ até peso constante e as cinzas, por calcinagem em mufla a $550{ }^{\circ} \mathrm{C}$ até peso constante. Os teores de $\mathrm{N}$ foram determinados segundo $\mathrm{AOAC}^{9} \mathrm{e}$ os teores de FDN conforme Van Soest et al. ${ }^{10}$.

Ao início e ao final de cada período, o desempenho dos animais também foi monitorado por meio de pesagens, após jejum de sólidos e líquidos de 12 horas. O ganho médio diário de peso vivo (GMD) foi obtido por meio da diferença do peso inicial e final dos animais em cada período experimental. Ao momento das pesagens também foram avaliados os escores de condição corporal (ECC), atribuindo-se pontuações de 1 a 5 , sendo $1=$ muito magro e $5=$ =muito gordo, conforme descrito por Lowman ${ }^{11}$.

A determinação da taxa de lotação em $\mathrm{kg} / \mathrm{ha}$ de PV foi obtida a partir do produto do somatório do peso vivo dos animais testes e peso dos animais reguladores multiplicado pelo número de dias que estes últimos permaneceram na pastagem, dividido pelo número de dias do período, conforme descrito por PIZZUTI et al. ${ }^{6}$.

O ganho médio diário por área (GMDA), que representa o ganho de peso vivo/ha obtido por dia, foi determinado pelo produto entre a taxa de lotação e o ganho médio diário dos animais testes pela razão desse com o peso vivo médio dos animais testes. $\mathrm{O}$ ganho de peso vivo por período (GPVP), que representa o ganho de peso vivo/ha obtido por período, foi calculado através do produto do GMDA pelo número de dias do período de avaliação. $\mathrm{O}$ ganho de peso vivo total/hectare (GPV), que representa o ganho de peso vivo total obtido por hectare ao longo do experimento, foi obtido a partir do produto do GMDA pelo número de dias de utilização das pastagens (63 dias).

$\mathrm{O}$ delineamento experimental utilizado foi o inteiramente casualizado, com medidas repetidas no tempo, considerando os cinco piquetes de cada tratamento como repetição. $\mathrm{O}$ arranjo fatorial foi de $2 \times 3$ (dois tratamentos e três períodos). Todas as variáveis foram testadas quanto à normalidade pelo teste Shapiro-Wilk, sendo realizadas as transformações, quando necessárias, nas seguintes variáveis: relação de folha/colmo e ganho de escore de condição corporal. Posteriormente, realizaram-se a análise de variância e o teste $\mathrm{F}$, a $5 \%$ de significância, utilizando-se o PROC MIXED (modelos mistos).

Foram avaliados os efeitos da causa de variação principal (espécie e período), assim como as interações entre elas. Quando as variáveis apresentavam diferenças significativas a $5 \%$, essas eram submetidas a teste de comparação de médias pelo teste "t" de student a 5\% de significância.

O modelo matemático utilizado para análise de variância foi:

$$
\mathrm{Y}_{\mathrm{ijk}}=\mu+\mathrm{T}_{\mathrm{i}}+\mathrm{R}_{\mathrm{k}}\left(\mathrm{T}_{\mathrm{i}}\right)+\mathrm{P}_{\mathrm{j}}+(\mathrm{TP})_{\mathrm{ij}}+\mathrm{e}_{\mathrm{ijk}}
$$

Considerando: $Y_{\mathrm{ijk}}$ as variáveis dependentes; $\mu$ a medida de todas as observações; $T_{i} o$ efeito do iésimo tratamento; $R_{k}\left(T_{i}\right)$ o efeito da k-ésima repetição dentro do i-ésimo tratamento (erro a); $\mathrm{P}_{\mathrm{j}} \mathrm{o}$ efeito do j-ésimo período; $(\mathrm{TP})_{\mathrm{ij}}$ a interação entre o iésimo tratamento e o j-ésimo período; e $\mathrm{e}_{\mathrm{ijk}} \mathrm{o}$ erro experimental total (erro b).

\section{RESULTADOS E DISCUSSÃO}

As precipitações médias, observadas nos meses que transcorreram as atividades de plantio, e o estabelecimento das pastagens e pastejo, apresentaram valores que oscilaram próximos às médias dos últimos 30 anos de observações (Tabela 1). No mês de dezembro, foi observada precipitação em torno de $18,2 \%$ superior à média para o período, o que permitiu o desenvolvimento das pastagens e a entrada dos animais para o rebaixamento da massa de forragem, 30 dias após o plantio. Entretanto, o mês de janeiro apresentou redução de $12,4 \%$ na precipitação, em comparação à média dos últimos 30 anos, justamente no período pós-rebaixamento da pastagem, retardando seu desenvolvimento e, por consequência, seu restabelecimento.

Tabela 1 - Médias de temperatura máxima $\left(\mathrm{T}^{\circ} \mathrm{C}\right.$ Máx.), mínima $\left({ }^{\circ}{ }^{\circ} \mathrm{C}\right.$ Mín. $)$, média $\left(\mathrm{T}{ }^{\circ} \mathrm{C}\right.$ Média), precipitação (mm) e insolação (horas), observadas (O) nos meses de dezembro de 2010 a abril de 2011, e média dos últimos 30 anos de observação (M)

\begin{tabular}{lcccccccccc}
\hline \multirow{2}{*}{ Mês } & \multicolumn{2}{c}{$\mathrm{T}^{\circ} \mathrm{C}$ Máx. } & \multicolumn{2}{c}{$\mathrm{T}^{\circ} \mathrm{C}$ Mín. } & \multicolumn{2}{c}{$\mathrm{T}^{\circ} \mathrm{C}$ Média } & \multicolumn{2}{c}{ Precip. mm } & \multicolumn{2}{c}{ Insol. - hs } \\
\cline { 2 - 11 } & $\mathrm{M}$ & $\mathrm{O}$ & $\mathrm{M}$ & $\mathrm{O}$ & $\mathrm{M}$ & $\mathrm{O}$ & $\mathrm{M}$ & $\mathrm{O}$ & $\mathrm{M}$ & $\mathrm{O}$ \\
\hline Dezembro & 29,5 & 30,4 & 18,3 & 18,4 & 22,7 & 24,3 & 133,5 & 157,8 & 244,7 & 111,3 \\
Janeiro & 30,4 & 32,4 & 19,1 & 19,4 & 24,6 & 25,6 & 145,1 & 127,1 & 225,2 & 246,9 \\
Fevereiro & 30,0 & 29,9 & 19,5 & 21,0 & 24,0 & 24,6 & 130,2 & 165,8 & 196,7 & 195,4 \\
Março & 28,2 & 28,9 & 17,9 & 18,6 & 22,2 & 22,5 & 151,7 & 54,9 & 197,5 & 229,4 \\
Abril & 25,0 & 26,6 & 14,5 & 14,9 & 18,8 & 19,4 & 134,7 & 164,9 & 168,7 & 192,2 \\
\hline
\end{tabular}

Fonte: Estação meteorológica da Universidade Federal de Santa Maria (2012). 
No mês de fevereiro ocorreu precipitação de $27,3 \%$ acima da média para esse período, contribuindo para as elevadas taxas de acúmulo diário ( $\mathrm{kg}$ de $\mathrm{MS} / \mathrm{ha}$ dia) nos primeiros 21 dias experimentais (Tabela 5). Entretanto, no mês de março, a precipitação foi $63,8 \%$ abaixo da média para o período, fazendo com que a participação de espécies indesejadas aumentasse bruscamente, provocando mudanças severas nos demais parâmetros das pastagens (Tabelas 3 e 5). Hoffman et al. $^{12}$ afirmaram que o pasto é um recurso nutricional basal de elevada complexidade, uma vez que sua capacidade de fornecimento de substrato para a produção animal varia qualitativamente e quantitativamente ao longo do ano, devido à interferência de variáveis climáticas, como a precipitação, temperatura e radiação solar ${ }^{13}$.

Não houve interação entre tratamento e período, tampouco efeito dos tratamentos $(\mathrm{P}<0,05)$ para os componentes morfológicos/botânicos e características qualitativas das pastagens (Tabela 2). Com o avanço do ciclo vegetativo das gramíneas, porém, a participação de outras espécies, principalmente do capim papuã, (Urochloa plantaginea $)$ aumentou $(\mathrm{P}<0,0001)$, enquanto a participação de lâminas foliares e colmos das espécies estudadas na composição botânica das pastagens $(\mathrm{P}<0,0001)$ diminuiu, refletindo nos aspectos qualitativos do pasto (Tabela 3 ).

Tabela 2 - Percentual dos componentes lâmina foliar, colmo, outros, matéria morta, matéria seca (MS), proteína bruta $(\mathrm{PB})$ e fibra em detergente neutro $(\mathrm{FDN})$ de pastagens de milheto ou capim sudão

\begin{tabular}{|c|c|c|c|c|}
\hline \multirow[t]{2}{*}{ Variáveis } & \multicolumn{2}{|c|}{ Tratamentos } & \multirow[t]{2}{*}{ Erro-Padrão } & \multirow[t]{2}{*}{$\mathrm{P}$} \\
\hline & Milheto & Sudão & & \\
\hline Lâmina foliar, \% & 14,75 & 18,63 & 1,88 & 0,1841 \\
\hline Colmo, $\%$ & 15,43 & 16,49 & 1,46 & 0,6216 \\
\hline Outros, $\%$ & 48,38 & 45,59 & 2,07 & 0,3682 \\
\hline Matéria-Morta, \% & 21,76 & 21,29 & 1,67 & 0,8454 \\
\hline Matéria Seca, \% & 22,20 & 23,39 & 0,63 & 0,2590 \\
\hline Proteína Bruta, \% & 13,61 & 13,06 & 0,64 & 0,5425 \\
\hline Fibra em Detergente Neutro, \% & 52,34 & 50,57 & 0,74 & 0,1321 \\
\hline
\end{tabular}

$\mathrm{P}=$ Probabilidade $/ \mathrm{P}<0,05$.

Os teores de MS foram superiores no terceiro período experimental $(25,04 \%)$ comparado ao primeiro $(21,56 \%)$ e segundo $(21,65 \%)$ períodos experimentais. Da mesma forma, os valores de PB foram maiores nos primeiros 21 dias de pastejo $(17,04 \%)$, seguidos de reduções no período $22-42$ dias $(12,96 \%)$ e nova redução nos últimos 21 dias de utilização das pastagens $(10,01 \%)$. O valor de FDN, por outro lado, manteve-se constante nos primeiros 42 dias de pastejo, com aumentos $(\mathrm{P}<0,05)$ nos últimos 21 dias de utilização das pastagens.

A redução da qualidade das pastagens com o avançar do ciclo vegetativo é comum em forrageiras de estação quente ${ }^{1}$; entretanto, essa tendência foi agravada no presente estudo pelo aumento na participação de espécies indesejadas (Outros) na composição botânica das pastagens, nos últimos 42 dias de utilização, comprovados pelos coeficientes de correlação entre PB e FDN com Outros $(r=-0,65$;
$\mathrm{P}<0,0001$ e $\mathrm{r}=0,56 ; \mathrm{P}=0,0014$, respectivamente), promovendo aumento nos teores de FDN e redução nos de PB. No estudo de Menezes et al. ${ }^{14}$, desenvolvido na mesma área experimental que a do presente trabalho, os autores verificaram teores de PB e FDN de 9,63 e 52,85\% (base na MS), a partir de amostras de simulação de pastejo de novilhos em pastagens de milheto. Os autores também evidenciaram que a baixa qualidade das pastagens se deveu à alta presença da gramínea capim-papuã (Urochloa plantaginea).

Os valores para massa de forragem (MF), taxa de acúmulo diário (TAD), oferta de forragem (OF), oferta de lâminas foliares (OFL), relação de folha/colmo $(\mathrm{F} / \mathrm{C})$ e perdas de forragem (Perdas) não demonstraram interação entre tratamento e período, sendo esses similares entre os tratamentos (Tabela $4)$. 
Tabela 3 - Percentual dos componentes lâmina foliar, colmo, outros e matéria morta (MM) e dos teores de matéria seca, proteína bruta (PB) e fibra em detergente neutro (FDN), em relação ao período experimental

\begin{tabular}{lcccccc}
\hline Variáveis & \multicolumn{3}{c}{ Períodos (dias) } & Média & $\begin{array}{c}\text { Erro- } \\
\text { Padrão }\end{array}$ & $\mathrm{P}$ \\
\cline { 2 - 4 } & $1-21$ & $22-42$ & $43-63$ & & & \\
\cline { 2 - 5 } Lâmina foliar, \% & $30,08^{\mathrm{a}}$ & $14,98^{\mathrm{b}}$ & $5,02^{\mathrm{c}}$ & 16,69 & 0,92 & $<0,0001$ \\
Colmo, \% & $25,65^{\mathrm{a}}$ & $16,63^{\mathrm{b}}$ & $5,61^{\mathrm{c}}$ & 15,96 & 1,78 & $<0,0001$ \\
Outros, \% & $28,02^{\mathrm{c}}$ & $45,67^{\mathrm{b}}$ & $67,26^{\mathrm{a}}$ & 46,98 & 1,62 & $<0,0001$ \\
MM, \% & 18,76 & 23,70 & 22,11 & 21,52 & 0,57 & 0,3885 \\
Matéria Seca, \% & $21,56^{\mathrm{b}}$ & $21,65^{\mathrm{b}}$ & $25,04^{\mathrm{a}}$ & 22,75 & 0,84 & 0,0012 \\
PB, \% & $17,04^{\mathrm{a}}$ & $12,96^{\mathrm{b}}$ & $10,01^{\mathrm{c}}$ & 13,34 & 0,77 & $<0,0001$ \\
FDN, \% & $48,81^{\mathrm{b}}$ & $49,01^{\mathrm{b}}$ & $56,54^{\mathrm{a}}$ & 51,45 & 0,91 & $<0,0001$ \\
\hline
\end{tabular}

$\mathrm{P}=$ Probabilidade/ $\mathrm{P}<0,05$.

Letras minúsculas distintas na mesma linha diferem entre si $(\mathrm{P}<0,05)$.

Tabela 4 - Massa de forragem disponível (MF), taxa de acúmulo (TAD), oferta de forragem (OF), oferta de lâminas foliares (OFL), relação folha/colmo (F/C) e perdas de forragem (Perdas), de pastagens de milheto ou capim sudão

\begin{tabular}{lcccc}
\hline Variáveis & \multicolumn{2}{c}{ Tratamentos } & \multirow{2}{*}{ Erro-Padrão } & P \\
\cline { 2 - 3 } & Milheto & Sudão & & 65,88 \\
MF (kg de MS/ha) & $1.606,93$ & $1.617,47$ & & 0,8881 \\
TAD (kg de MS/ha/dia) & 80,52 & 74,43 & 7,12 & 0,5624 \\
OF (kg de MS/100 kg de PV) & 9,42 & 8,29 & 0,60 & 0,2185 \\
OFL (kg de MS/100 kg de PV) & 2,79 & 2,43 & 0,25 & 0,3453 \\
F/C & 0,76 & 0,78 & 0,08 & 0,8871 \\
Perdas (kg MS/período) & 261,27 & 236,14 & 26,35 & 0,5191 \\
\hline
\end{tabular}

$\mathrm{P}=$ Probabilidade $/ \mathrm{P}<0,05$.

Os valores médios para a TAD de 80,52 $\mathrm{kg} / \mathrm{ha}$ de MS nas pastagens de milheto e de 74,43 $\mathrm{kg} / \mathrm{ha}$ de MS nas de capim sudão poderiam ser maiores, uma vez que a implantação de pastagens anuais de estação quente no Rio Grande do Sul pode ser iniciada em meados do mês de outubro e início de novembro, período esse que, além de coincidir com o aumento na disponibilidade de área para o plantio de culturas anuais de verão, em função do término do ciclo das culturas anuais de inverno, também é favorecido pelas condições climáticas (temperatura do solo e precipitação), favoráveis à implantação dessas pastagens. Nessas condições, a entrada definitiva dos animais para pastejo poderia ocorrer no início do mês de dezembro, aproximadamente 60 dias antes do presente estudo, o que refletiria de forma expressiva em maiores TAD e, principalmente, maiores médias de ganhos de peso dos animais obtidos por área, devido ao maior tempo de utilização das pastagens, conforme será discutido posteriormente.

Os valores obtidos para MF estavam abaixo $(1.610,7 \mathrm{~kg} / \mathrm{ha}$ de MS) do preconizado $(2.000 \mathrm{~kg} / \mathrm{ha}$ de MS) e semelhantes entre os três períodos de avaliação das pastagens $(1.514,6 ; 1748,8 ; 1.568,7$ $\mathrm{kg} / \mathrm{ha}$ de MS) (Tabela 5). Esse fato se deve às dificuldades encontradas pelas espécies, alvo do estudo, em se restabelecerem após o primeiro pastejo (janeiro). Esse retardo contribuiu para que o início da utilização das pastagens fosse com massas de forragem abaixo do preconizado. No entanto, a constância nas médias de MF ao longo dos períodos de utilização das pastagens, assim como da OF, evidencia que o manejo empregado foi adequado, uma vez que a variável MF foi controlada de forma a não oscilar em função dos períodos.

As TAD, OFL, $\mathrm{F} / \mathrm{C}$ e Perdas foram influenciadas pelos períodos $(\mathrm{P}<0,05)$. As diferenças nessas variáveis ao longo dos períodos de utilização das pastagens eram esperadas, uma vez que, com o avanço do ciclo vegetativo das plantas, ocorrem mudanças fisiológicas que alteram seu metabolismo e ritmo de crescimento, afetando além da taxa de crescimento da pastagem também sua composição estrutural e química.

A OF de $8,85 \mathrm{~kg}$ de MS/100kg de PV foi de 3 a 4 vezes a capacidade de ingestão de MS dos ruminantes, independente do período $(9,23 ; 8,11$; 
9,21 kg de MS /100 PV). Esses valores são semelhantes aos relatados por Pötter et al. ${ }^{15}$ como ideais para bovinos em pastejo que, segundo os autores, devem ser 3 vezes e meia maior que o consumo máximo de MS (2,5 kg de MS/ $100 \mathrm{~kg}$ de PV) (16).

A OFL nos primeiros 21 dias de utilização das pastagens $(3,63 \%)$ foi acima das médias dos outros dois períodos experimentais subsequentes (1,98 e 2,23\%). Esses resultados são justificados em função das mudanças ocorridas na variável relação folha/colmo, a qual também demonstrou médias superiores no primeiro período $(1,15)$ que nos demais períodos experimentais consecutivos $(0,58 \mathrm{e}$ 0,57). Por outro lado, a OFL do período $22-42$ dias foi inferior à do período 43-63 dias (1,98 contra 2,23 $\%)$.

Esperavam-se maiores valores para a OFL no período 22-42 dias do que no período 43-63 dias; no entanto, isso não se confirmou. Esse resultado é provavelmente devido à diferença numérica na oferta de forragem no segundo período, embora não tenha diferido estatisticamente entre os períodos, ela representa $12 \%$ a menos que nos demais períodos; em outras palavras, como a porcentagem de lâminas foliares decresceu (Tabela 3) no decorrer dos períodos, isso se repercutiu na oferta de laminas foliares. Aliado a isso, a maior participação de espécies indesejadas (principalmente o capim-papuã) na composição botânica das pastagens, ocorrida de forma mais acentuada nos últimos 21 dias de utilização das pastagens (período 43-63 dias), contribuiu para a maior OFL no último período, quando comparado ao de 22-42 dias. O capim-papuã, espécie com maior representatividade em Outros no presente trabalho, no período entre março a abril, demonstra bom potencial vegetativo17, característica que oportunizou maiores ofertas de folhas durante março e abril. Segundo Euclides et al. ${ }^{18}$, a faixa ideal para a oferta de lâminas foliares é de 4 a $11 \mathrm{~kg} / 100$ $\mathrm{kg}$ dia.

Tabela 5- Massa de forragem disponível (MF), taxa de acúmulo (TAD), oferta (OF), oferta de lâminas foliares (OFL), relação folha/colmo (F/C) e perdas de forragem (Perdas) em relação ao período de avaliação

\begin{tabular}{|c|c|c|c|c|c|c|}
\hline \multirow[t]{2}{*}{ Variáveis } & \multicolumn{3}{|c|}{ Períodos (dias) } & \multirow[t]{2}{*}{ Média } & \multirow{2}{*}{$\begin{array}{l}\text { Erro- } \\
\text { Padrão }\end{array}$} & \multirow[t]{2}{*}{$\mathrm{P}$} \\
\hline & $1-21$ & $22-42$ & $43-63$ & & & \\
\hline MF (kg de MS/ha) & 1514,6 & 1748,8 & 1568,7 & 1610,7 & 80,68 & 0,1315 \\
\hline TAD (kg de MS/ha/dia) & $130,77^{\mathrm{a}}$ & $65,53^{\mathrm{b}}$ & $36,13^{\mathrm{c}}$ & 77,48 & 7,80 & $<0,0001$ \\
\hline OF ( $\mathrm{kg}$ de MS/100 kg de PV) & 9,23 & 8,11 & 9,21 & 8,85 & 0,68 & 0,4823 \\
\hline OFL ( $\mathrm{kg}$ de $\mathrm{MS} / 100 \mathrm{~kg}$ de PV) & $3,63^{\mathrm{a}}$ & $1,98^{\mathrm{c}}$ & $2,23^{\mathrm{b}}$ & 2,61 & 0,25 & 0,0064 \\
\hline $\mathrm{F} / \mathrm{C}$ & $1,15^{\mathrm{a}}$ & $0,58^{\mathrm{b}}$ & $0,57^{\mathrm{b}}$ & 0,77 & 0,11 & 0,0031 \\
\hline Perdas (kg MS/período) & $284,55^{\mathrm{a}}$ & $304,1^{\mathrm{a}}$ & $157,55^{b}$ & 248,73 & 32,27 & 0,0109 \\
\hline
\end{tabular}

$\mathrm{P}=$ Probabilidade $/ \mathrm{P}<0,05$.

Letras minúsculas distintas na mesma linha diferem entre si $(\mathrm{P}<0,05)$.

Embora seja reconhecida a influência da OFL sobre as variáveis de desempenho de animais em pastejo ${ }^{19,20}$, ela não se correlacionou com o ganho médio diário das vacas, demonstrando que, possivelmente, o consumo de colmos pode ter sido expressivo na dieta dos animais. No entanto, a OFL afetou o comportamento ingestivo, uma vez que as variáveis tempo de pastejo e taxa de bocados por minuto $^{21}$ demonstraram correlações negativas com a variável que representa a participação de folhas na estrutura das pastagens $(\mathrm{r}=0,32 ; \mathrm{P}=0,0127$ e $\mathrm{r}=$ 0,$28 ; \mathrm{P}=0,0298$ ).

A relação folha/colmo variou em função dos períodos. No primeiro período, essa relação foi maior que nos períodos subsequentes, sendo a relação folha/colmo igual nos dois últimos períodos. A similaridade nos dois últimos períodos se deve à maior percentagem de colmo comparado à folha no segundo período, o que tornou a relação igual ao terceiro período. A relação folha/colmo pode ser um bom indicativo do valor nutritivo da pastagem. Segundo Carvalho et $\mathrm{al}^{22}$, além da relação folha/colmo, a altura da pastagem e a disponibilidade de biomassa afetam o comportamento ingestivo dos animais, promovendo redução no desempenho animal, como reflexo da qualidade da forragem.

As perdas de forragem foram semelhantes nos primeiros 42 dias de utilização das pastagens, com reduções nos últimos 21 dias $(\mathrm{P}<0,05)$. A tendência esperada para essa variável, com o avançar do ciclo vegetativo, é de aumento da participação no resíduo na pastagem, em função da maior participação de tecido morto e reduções no acúmulo de forragem; entretanto, esse comportamento não foi observado no presente estudo. Os aumentos acentuados na participação de espécies indesejadas 
(principalmente o capim-papuã) na composição botânica da pastagem (Tabela 3) podem ter gerado reduções na intensidade de senescência nos últimos 21 dias experimentais, uma vez que o ciclo vegetativo do capim papuã é maior do que o de espécies anuais de estação quente. Essa característica fez com que o início do processo de senescência nessas pastagens fosse mais tardio, permitindo, dessa forma, que as perdas de forragem nesse período fossem reduzidas.

A taxa de lotação representada em $\mathrm{kg} / \mathrm{ha}$ de PV demonstrou interação entre tratamento e período $(\mathrm{P}=0,0365$; Tabela 6). Os valores observados nas pastagens de capim sudão, nos primeiros 21 dias de utilização, foram superiores aos das pastagens de milheto nesse mesmo período e também às obtidas nos demais períodos experimentais, independente do tratamento.

Não houve diferença entre períodos para as médias de taxa de lotação para os tratamentos das pastagens de milheto (primeiros 42 dias) e sudão (22-42 dias). No entanto, a taxa de lotação nos últimos 21 dias de utilização das pastagens de milheto e de capim Sudão foram inferiores $(\mathrm{P}<0,05)$ à dos primeiros 42 dias, obtidas nas pastagens de milheto que, por sua vez, foram semelhantes às lotações observadas no período de 22-42 dias de capim sudão. Na comparação das médias de taxa de lotação, independente do tratamento, observou-se que a variável manteve-se constante nos primeiros 42 dias, seguida de redução nos últimos 21 dias experimentais.

Tabela 6 - taxa de lotação em pastagens de milheto ou capim sudão de acordo com o período de avaliação

\begin{tabular}{lcccccc}
\hline \multirow{2}{*}{ Tratamentos } & \multicolumn{3}{c}{ Taxa de lotação (kg/ha de PV) } & Média & Erro-padrão & P \\
\cline { 2 - 4 } & \multicolumn{3}{c}{ Período (dias) } & & & \\
\cline { 2 - 4 } & $1-21$ & $22-42$ & $43-63$ & & \\
\hline Milheto & $1.980,6^{\mathrm{b}}$ & $1.991,0^{\mathrm{b}}$ & $1.251,6^{\mathrm{c}}$ & $1.741,1$ & 92,18 & 0,0365 \\
Sudão & $2.677,8^{\mathrm{a}}$ & $1.696,0^{\mathrm{bc}}$ & $1.271,4^{\mathrm{c}}$ & $1.881,7$ & & \\
Média & $2.329,2^{\mathrm{A}}$ & $1.843,5^{\mathrm{A}}$ & $1.261,5^{\mathrm{B}}$ & & & \\
\hline
\end{tabular}

$\mathrm{P}=$ Probabilidade $/ \mathrm{P}<0,05$

Letras minúsculas distintas nas linhas e colunas diferem entre si $(\mathrm{P}<0,05)$.

Letras maiúsculas distintas nas linhas diferem entre si $(\mathrm{P}<0,05)$.

Os valores observados para a taxa de lotação dos tratamentos milheto ou sudão nos 63 dias experimentais de utilização das pastagens foram semelhantes, com valor médio de 1.811,4. Esses valores foram superiores aos observados por Restle et al. ${ }^{1}$ em pastagem de sorgo ou milheto $(1.389 \mathrm{e}$ $1.514 \mathrm{~kg} / \mathrm{ha} \mathrm{de} \mathrm{PV}$, respectivamente).

Não houve interação entre tratamento e período para as variáveis de desempenho, assim como o efeito de tratamento também foi similar sobre as características de desempenho das vacas (Tabela 7). A igualdade observada nos parâmetros produtivos das pastagens (Tabela 4) estendeu-se às características de desempenho dos animais. Segundo Reis et al. ${ }^{23}$, o desempenho animal em pastagem é determinado principalmente pela qualidade da forragem, sendo esta, por sua vez, função do valor nutritivo e consumo voluntário. Para os autores, o manejo do pastejo exerce papel primordial no contexto alimentar dos animais, de forma que as variáveis massa de forragem, estrutura do dossel forrageiro, oferta de folhas, colmo e material morto são fatores determinantes que afetam $o$ comportamento ingestivo e por consequência o consumo de nutrientes. Os resultados do presente estudo evidenciam a equivalência entre as pastagens de milheto ou capim sudão, demonstrando que o capim sudão pode ser uma alternativa ao milheto, quando destinados à alimentação de vacas para abate.

Os valores obtidos para GMDA, que mede o ganho médio diário de peso vivo por hectare/dia, e GPV, que representa o ganho de peso vivo total obtido ao longo do período de utilização da pastagem, foram de $3,83 \mathrm{~kg} / \mathrm{ha} / \mathrm{dia}$ e $241,51 \mathrm{~kg} / \mathrm{ha}$ na pastagem de milheto e $3,58 \mathrm{~kg} / \mathrm{ha} / \mathrm{dia}$ e $225,85 \mathrm{~kg} / \mathrm{ha}$ na de capim sudão, respectivamente. Os valores para essas duas variáveis podem ser considerados adequados aos sistemas de produção de bovinos de corte que almejam a retornos econômicos por área satisfatórios, pois, quando se comparam aos resultados médios observados em sistemas produtivos que fazem uso exclusivo de pastagem natural, valores médios de $82 \mathrm{~kg} /$ ha são obtidos durante o período de verão ${ }^{24}$; no entanto, quando a comparação é realizada com médias de produção obtidas em estudos com forrageiras de estação quente cultivadas, é possível classificá-los como abaixo do potencial para esse grupo. Restle et al. ${ }^{1}$, ao compararem diferentes forrageiras de estação quente 
na terminação de novilhos, obtiveram valores de $570,3 \mathrm{~kg} / \mathrm{ha}$ em pastagens de sorgo e $639,9 \mathrm{~kg} / \mathrm{ha} \mathrm{em}$ milheto, ambas durante 98 dias de pastejo. Os valores de GPV (kg/ha) no presente trabalho estão aquém do potencial das espécies, pois estão intimamente ligados ao curto período de utilização das pastagens (63 dias). Também estão relacionados à categoria animal (vacas de descarte) que foi utilizada nas pastagens, uma vez que, em sistemas de produção com categorias mais jovens, o GMDA é otimizado, em função da maior eficiência biológica dos animais.

O GMD não variou significativamente com o avanço do ciclo das pastagens: 0,82;1,19 e 1,0 kg (Tabela 8); entretanto, nos últimos 21 dias, o GMDA e o GPVP reduziram em aproximadamente $47 \% \mathrm{em}$ relação aos primeiros 42 dias de utilização das pastagens (Tabela 8). Esse comportamento seguiu a mesma tendência observada nos valores da taxa de lotação, confirmados pelos coeficientes de correlação entre essas variáveis $(\mathrm{r}=0,57, \mathrm{P}=0,0010)$, tanto para a taxa de lotação com o GMDA, como com o GPV.

Tabela 7 - Peso inicial (kg), peso final (kg), ganho médio diário de peso vivo (GMD), escore de condição corporal final (ECC final), ganho de escore de condição corporal (GECC), ganho médio diário por hectare (GMDA) e ganho de peso vivo total por área (GPV) de pastagens de milheto ou capim sudão

\begin{tabular}{lcccc}
\hline Variáveis & \multicolumn{2}{c}{ Tratamentos } & \multirow{2}{*}{ Erro Padrão } & P \\
\cline { 2 - 3 } & Milheto & Sudão & & \\
\hline Peso inicial (kg) & 450,9 & 447,0 & 7,12 & 0,8930 \\
Peso final (kg) & 512,6 & 511,3 & 13,21 & 0,9228 \\
GMD (kg) & 1,04 & 0,96 & 0,06 & 0,3921 \\
ECC final (pontos) & 3,43 & 3,27 & 0,12 & 0,1971 \\
GECC (pontos) & 0,254 & 0,209 & 0,05 & 0,5344 \\
GMDA (kg/ha/dia) & 3,83 & 3,58 & 0,39 & 0,6624 \\
GPV (kg/ha nos 63 dias de utilização) & 241,51 & 225,85 & 23,12 & 0,6383 \\
\hline
\end{tabular}

$\mathrm{P}=$ Probabilidade $/ \mathrm{P}<0,05$.

Tabela 8 - Ganho médio diário (GMD), ganho de escore de condição corporal (GECC), ganho médio diário por área (GMDA) e ganho de peso total no período (GPVP), em relação ao período de avaliação

\begin{tabular}{lcccccc}
\hline Variáveis & \multicolumn{3}{c}{ Períodos } & Média & $\begin{array}{c}\text { Erro- } \\
\text { Padrão }\end{array}$ & $\mathrm{P}$ \\
\cline { 2 - 4 } & $1-21$ & $22-42$ & $43-63$ & & 0,13 & 0,1718 \\
GMD (kg) & 0,82 & 1,19 & 1,00 & 1,00 & 0,13 & 0,5591 \\
GECC (pontos) & 0,28 & 0,20 & 0,22 & 0,23 & 0,06 & $0,5,20120$ \\
GMDA (kg/ha por dia) & $4,18^{\mathrm{a}}$ & $4,55^{\mathrm{a}}$ & $2,39^{\mathrm{b}}$ & 3,71 & 0,47 & 0,012 \\
GPVP (kg/ha por período) & $87,76^{\mathrm{a}}$ & $95,59^{\mathrm{a}}$ & $50,32^{\mathrm{b}}$ & 77,89 & 9,95 & 0,0119 \\
\hline
\end{tabular}

$\mathrm{P}=$ Probabilidade/ $\mathrm{P}<0,05$.

Letras maiúsculas distintas nas linhas diferem entre si $(\mathrm{P}<0,05)$.

Embora a média de taxa de lotação tenha demonstrado valores superiores às de outros estudos com forrageiras de estação quente ${ }^{1}$, como discutido anteriormente, o que poderia condicionar alto GMDA e por consequência elevado GPV, isso não ocorreu no presente trabalho. Dentro de uma ótica mais ampla do sistema de produção, os resultados indiretos obtidos com a alimentação das vacas para abate nas pastagens de milheto ou capim sudão contribuem para a otimização de áreas destinadas à bovinocultura de corte, porque essas permitem alta capacidade de suporte, quando são comparadas a pastagens nativas, além de disponibilizar áreas de pastagem natural para a produção de outras categorias, uma vez que nessas é comum a terminação de vacas para abate.

Além disso, a média de GMD obtido com vacas (de $1,0 \mathrm{~kg}$ ) são valores que não são obtidos em pastagem nativa, o que reduz o tempo de permanência dessas fêmeas na propriedade e torna mais eficiente o sistema de produção. Osmari et al. ${ }^{25}$ observaram ganhos de peso de $0,775 \mathrm{~kg}$ e $0,776 \mathrm{~kg}$ em vacas terminadas em pastagem natural no período de março a junho com suplementação de $0,5 \%$ do PV de farelo de arroz integral e farelo de trigo, respetivamente. 
A premissa de que o capim sudão apresenta alta resistência ao déficit hídrico e, em função disso, pode apresentar maior produção de forragem em condições adversas, quando comparado ao milheto, não se confirmou no presente estudo. Essa condição ocorreu provavelmente devido às reduções bruscas na precipitação pluviométrica observada no mês de março, que afetaram de forma igualitária os tratamentos milheto e sudão, contribuindo para o avanço de gramíneas indesejadas, como o capimpapuã. Entretanto, o capim sudão demonstrou características produtivas semelhantes ao milheto, direcionando à igualdade nos ganhos de peso individual e por área dos animais, demonstrando ser uma forrageira de potencial para esse tipo de sistema de produção.

\section{CONCLUSÕES}

Pastagens de milheto ou capim sudão, submetidas à pastejo continuo, são semelhantes quanto aos parâmetros produtivos e condicionam ganhos individuais satisfatórios de vacas para abate em terminação. No entanto, a maximização do período de utilização dessas espécies é determinante no sucesso do sistema de produção.

\section{REFERÊNCIAS}

1. Restle, J.; Roso, C.; Aita, V.; Nornberg, J.L.; Brondani, I.L.; Cerdótes, L. Carrilo, C.O. Produção Animal em Pastagem com Gramíneas de Estação Quente. Revista Brasileira de Zootecnia. 2002;31:1491-1500. Disponível em: $\quad$ http://www.scielo.br/scielo.php?pid=S1516$35982002000600021 \&$ script $=$ sci_arttext

2. Tomich, T.R.; Tomich, R.G.P.; Gonçalves, L.C.; Borges, I.; Rodrigues, J.A.S. Valor nutricional de híbridos de sorgo com capim-sudão em comparação ao de outros volumosos utilizados no período de baixa disponibilidade das pastagens. Arquivo Brasileiro de Medicina Veterinária e Zootecnia, v.58, n.6, p.1249-1252, 2006. Disponível em: http://www.scielo.br/pdf/abmvz/v58n6/43.pdf

3. Missio, R.L.; Restle, J.; Moletta, J.L.; Kuss, F.; Neiva, J.N.M.; Moura, C.F.M. Características da carcaça de vacas de descarte abatidas com diferentes pesos.Revista Ciência Agronômica. 2013; 44 (3):644-651. Disponível em: $\quad h$ ttp://www.scielo.br/scielo.php?pid=S1806$\underline{66902013000300029 \& \text { script }=\text { sci } \_ \text {arttext }}$

4. Instituto Brasileiro de Geográfia e Estatistica - IBGE Pesquisa da pecuária. 2013. Disponível em: http://www.sidra.ibge.gov.br/bda/tabela/listabl.asp?z=t\&o $=24 \& \mathrm{i}=\mathrm{P} \& \mathrm{c}=1092$

5. Wilm, H.G.; Costello, D.F.; Klipple, G.E. Estimating forage yield by the double sampling method. Journal of American Society of Agronomy. 1944; 36: 194-203. Disponível em:
https://dl.sciencesocieties.org/publications/aj/pdfs/36/3/AJ 0360030194

6. Pizzuti, L.A.D.; Filho, D.C.A.; Bronani, I.L.; Freitas, L.S.; Metz, P.A.M.; Callegaro, A.M.; Pacheco, R.F.; Pereira, L.B. Production parameters and forage loss of oat and rye grass pastures managed with beef heifers fed diets with energy supplementation. Revista Brasileira de Zootecnia. 2012; 41(8):1928-1936. Disponível em: http://www.scielo.br/scielo.php?script=sci_arttext\&pid=S 1516-35982012000800018

7. Sollenberger, L.E.; Moore, J. E.; Allen, V.G.; Pedreira, C.G.S. Reporting forage allowance in grazing experiments. Crop Science Society of America. 2005; 45:896-900,

2005. https://www.crops.org/publications/cs/abstracts/45/3/0896

8. Euclides, V.P.B.; Macedo, M.C.M.; Oliveira, M.P. Avaliação de diferentes métodos de amostragem sob pastejo. Revista Brasileira de Zootecnia. 1992; 21:691702. Disponível em: http://www.revista.sbz.org.br/artigo/visualizar.php?artigo $=724$.

9. Association of Official Analytical Chemistry A.O.A.C. Official methods of analysis. Washington. D.C. 1995; 2000p. Disponível em:http://www.eoma.aoac.org/methods/info.asp?ID=1508

10. Van Soest, P.J.; Robertson, J.B. Lewis, B.A. Methods for dietary fiber, neutral detergent fiber, and nonsttarch polisaccharides in relation to animal nutrition. Journal of Dairy Science. 1991; 74:3583-3597. Disponível em: http://download.journals.elsevierhealth.com/pdfs/journals/ 0022-0302/PIIS0022030291785512.pdf

11. Lowman, B.G.; Scott, N.; Smerwille, S. Condition scoring beef cattle. Edinburgh: East of Scotland College of Agriculture. 1973; 8p.

12. Hoffmann, A.; Moraes, E.H.B.K.; Mousquer, C.J.; Simioni, T.A.; Junior Gomes, F.; Ferreira, V.B.; Silva, H.M. Produção de bovinos de corte no sistema de pastosuplemento no período seco. Nativa, Sinop, 2014; 02(02):119-130. Disponível em: file:///C:/Users/Rangel/Desktop/1298-4864-1PB\%20(1).pdf

13. Detmann, E.; Paulino, M.F.; Cecon, P.R.; Valadares Filho, S.C.; Zervoudakis, J.T.; Cabral, L.S.; Leão, M.I.; Lana, R.P.; Ponciano, N.J. Níveis de proteína em suplementos para terminação de bovinos em pastejo durante o período de transição seca/águas: consumo voluntário e trânsito de partículas. Revista Brasileira de Zootecnia. 2005; 34(4):1371-1379. Disponível em: http://www.scielo.br/scielo.php?pid=S1516-

$35982005000400035 \&$ script $=$ sci arttext

14. Menezes, L.F.G.; Restle, J.; Brondani, I.L.; Silveira, M.F.; Freitas, L.S.; Pizzuti, L.A.D. Características da carcaça e da carne de novilhos superjovens da raça Devon terminados em diferentes sistemas de alimentação. Revista Brasileira de Zootecnia. 2010; 39:667-676. Disponível 
em:

http://www.scielo.br/scielo.php?script $=$ sci_arttext\&pid $=\mathrm{S}$ 1516-35982010000300028.

15. Pötter, L.; Rocha, M.G.; Roso, D.; Costa, V.G.; Glinke, C.L.; Rosa, A.N. Suplementação com concentrado para novilhas de corte mantidas em pastagens cultivadas de estação fria. Revista Brasileira de Zootecnia, 2010;
39(5):992-1001.

Disponível em:http://www.scielo.br/scielo.php?script=sci_arttext\&pi $\mathrm{d}=\mathrm{S} 1516-35982010000500008$

16. NATIONAL RESEARCH COUNCIL - NRC. Nutrient requirements of beef cattle. 7.ed. Washington D.C.: National Academy Press, 1996. 248p. Disponível em: http://www.nap.edu/catalog.php?record id=9791

Protocolado em: 28 maio 2013 Aceito em: 18 mar. 2014. 